\title{
Evaluation of Normothermic Machine Perfusion of Porcine Livers as a Novel Preclinical Model to Predict Biliary Clearance and Transporter-Mediated Drug-Drug Interactions Using Statins ${ }^{\text {S }}$
}

\author{
L. J. Stevens, A. Z. X. Zhu, P. P. Chothe, S. K. Chowdhury, J. M. Donkers, W. H. J. Vaes, \\ C. A. J. Knibbe, I. P. J. Alwayn, and E. van de Steeg
}

Department of Surgery, Leiden University Medical Centre (LUMC) Transplant Center, Leiden, The Netherlands (L.J.S., I.P.J.A.); The Netherlands Organization for Applied Scientific Research (TNO), Zeist, The Netherlands (L.J.S., J.M.D., W.H.J.V., E.v.d.S.); Quantitative Solutions (A.Z.X.Z.), Department of Drug Metabolism \& Pharmacokinetic (P.P.C., S.K.C.), Takeda Pharmaceutical International, Cambridge, Massachusetts; Division of Systems Biomedicine and Pharmacology, Leiden Academic Centre for Drug Research (LACDR), Leiden, The Netherlands (C.A.J.K.); and Department of Clinical Pharmacy, St. Antonius Hospital, Nieuwegein and Utrecht, The Netherlands (C.A.J.K.)

Received April 26, 2021; accepted June 23, 2021

\section{ABSTRACT}

There is a lack of translational preclinical models that can predict hepatic handling of drugs. In this study, we aimed to evaluate the applicability of normothermic machine perfusion (NMP) of porcine livers as a novel ex vivo model to predict hepatic clearance, biliary excretion, and plasma exposure of drugs. For this evaluation, we dosed atorvastatin, pitavastatin, and rosuvastatin as model drugs to porcine livers and studied the effect of common drug-drug interactions (DDls) on these processes. After 120 minutes of perfusion, $0.104 \mathrm{mg}$ atorvastatin $(n=3), 0.140 \mathrm{mg}$ pitavastatin $(n=5)$, or $1.4 \mathrm{mg}$ rosuvastatin $(n=4)$ was administered to the portal vein, which was followed 120 minutes later by a second bolus of the statin coadministered with OATP perpetrator drug rifampicin $(67.7 \mathrm{mg})$. After the first dose, all statins were rapidly cleared from the circulation (hepatic extraction ratio $>0.7$ ) and excreted into the bile. Presence of humanspecific atorvastatin metabolites confirmed the metabolic capacity of porcine livers. The predicted biliary clearance of rosuvastatin was found to be closer to the observed biliary clearance. A rank order of the DDI between the various systems upon coadministration with rifampicin could be observed: atorvastatin (AUC ratio 7.2) > rosuvastatin (AUC ratio 3.1) > pitavastatin (AUC ratio 2.6), which is in good agreement with the clinical DDI data. The results from this study demonstrated the applicability of using NMP of porcine livers as a novel preclinical model to study OATP-mediated DDI and its effect on hepatic clearance, biliary excretion, and plasma profile of drugs.

\section{SIGNIFICANCE STATEMENT}

This study evaluated the use of normothermic machine perfusion (NMP) of porcine livers as a novel preclinical model to study hepatic clearance, biliary excretion, plasma (metabolite) profile of statins, and OATP-mediated DDI. Results showed that NMP of porcine livers is a reliable model to study OATP-mediated DDI. Overall, the rank order of DDI severity indicated in these experiments is in good agreement with clinical data, indicating the potential importance of this new ex vivo model in early drug discovery.

\section{Introduction}

The liver is a complex organ involved in the uptake, metabolism, and biliary excretion of xenobiotics and endogenous compounds. Transporters located at the basolateral side of the plasma membrane, such as the organic anion transporting peptides (OATP) 1B1, 1B3, 2B1, $\mathrm{Na}^{+}$-taurocholate cotransporting polypeptide (NTCP), and the organic anion transporter 2, are involved in the uptake of drugs and endogenous

This work received no external funding.

No potential conflict of interest was reported by the authors.

https://dx.doi.org/10.1124/dmd.121.000521.

S This article has supplemental material available at dmd.aspetjournals.org. compounds from the portal and arterial circulation into hepatocytes. After uptake, compounds can be metabolized, for example by the cytochrome P450 family of enzymes, and subsequently effluxed into the bile across the canalicular membrane or back into the systemic circulation across the sinusoidal membrane (Yang et al., 2009). Several transporters are involved in the hepatic efflux, including multidrug resistance protein 1 (MDR1; P-glycoprotein), breast cancer resistance protein (BCRP), bile salt export pump (BSEP), and multidrug resistance-associated protein 2 (MRP2) at the canalicular membrane and multidrug resistance-associated protein 3 and 4 (MRP3 and MRP4) at the basolateral membrane. Concomitant administration of drugs that are substrates for the same transporters and/or metabolizing enzymes can result in a drug-drug interaction (DDI) affecting plasma as well as biliary levels of one of the drugs. As a result, this can change the drug concentration at

ABBREVIATIONS: ALT, alanine aminotransferase; AST, aspartate aminotransaminase; AUC, area under the concentration-time curve; AUCR, AUC ratio; BCRP, breast cancer resistance protein; BSEP, bile salt export pump; DDI, drug-drug interaction; GLUT1, glucose transporter 1; ICG, indocyanine green; IPRL, isolated perfused rat liver; MCT1, monocarboxylate transporter 1; MDR1, multidrug resistance protein 1; MRP1, multidrug resistance-associated protein 1; MRP2, multidrug resistance-associated protein 2; MRP3, multidrug resistance-associated protein 3; NMP, normothermic machine perfusion; NTCP, $\mathrm{Na}^{+}$-taurocholate cotransporting polypeptide; OATP, organic anion transporting polypeptide; OATP1B1, organic anion transporting polypeptide 1B1; OATP1B3, organic anion transporting polypeptide 1B3; OATP2B1, organic anion transporting polypeptide 2B1; PK, pharmacokinetics. 
the target, or it can even lead to toxicity (e.g., drug-induced liver injury). Therefore, interactions affecting hepatic uptake and biliary excretion are important to characterize in the preclinical phase of drug development (Ito et al., 1998; Fagerholm, 2008).

To evaluate the potential DDI for newly developed drugs, the Food and Drug Administration stated that it is important to understand the principal route of the drug's elimination and to understand the contribution and effect of the drug on transporters and metabolizing enzymes. DDI at the transporter level is especially important to characterize since they control the absorption, distribution, and elimination of the drug in various organs (https://www.fda.gov/regulatory-information/search-fdaguidance-documents/vitro-drug-interaction-studies-cytochrome-p450enzyme-and-transporter-mediated-drug-interactions). When a newly developed drug, for example, is intended to be used by a population that is likely to also use statins, the sponsor should examine the potential of the investigational drug to interact with OATP1B1/1B3 (https://www.fda. gov/regulatory-information/search-fda-guidance-documents/vitro-

drug-interaction-studies-cytochrome-p450-enzyme-and-transporter-mediateddrug-interactions).

To study complex processes such as transporter-enzyme interplay, potential DDI, and biliary excretion, physiologically relevant models are needed that recapitulate all functions of the liver, including the ability to produce bile (Stevens et al., 2020). The sandwich-cultured hepatocyte and rat liver perfusion models are known to capture these complex processes and are currently used to investigate hepatobiliary disposition of drugs. Unfortunately, these models have their own limitations. In vitro to in vivo translation often fails because of species differences or differences in transporter expression, resulting in difficulties in the prediction of plasma profiles after oral and intravenous administration (Guillouzo, 1998). Therefore, extrapolation of data obtained using rodent models is not feasible for the prediction of human PK and DDI (Gores et al., 1986; Guillouzo, 1998; Chu et al., 2013).

At present, research in the field of organ transplantation is focused on organ preservation techniques using machine perfusion. These pressure-driven perfusion machines are able to perfuse human and porcine livers at a physiologic pressure under oxygenated and normothermic conditions. Porcine organs are often used for method validation and device development, and it has been shown that normothermic machine perfusion (NMP) of the porcine liver is an excellent platform to study hepatic processes (Borie et al., 2001; Eshmuminov et al., 2020). The pig model is considered as a proper translational model because of anatomic, physiologic, and biochemical similarity to humans, and nowadays this model is increasingly used in biomedical research (Helke and Swindle, 2013). Compared with the rat model, the size of the pig model supports the collection of larger sample volumes, and there is the ability to take tissue biopsies in time. Furthermore, an advantage of using livers from pig origin is the similarity of phase I and phase II biotransformation reactions (Helke and Swindle, 2013), which was recently confirmed in a quantitative proteomic analysis comparing transporter and metabolizing enzyme expression in human and porcine liver (Elmorsi et al., 2020).

In this study, we evaluate using normothermic machine perfusion of porcine livers as a novel preclinical model to predict pharmacokinetic processes. Using three statins as model drug compounds (rosuvastatin, atorvastatin, and pitavastatin), we studied the transporter-mediated hepatic extraction and biliary excretion. Additionally, we examined the effect of rifampicin on the disposition of these three statins.

\section{Materials and Method}

Chemicals. Atorvastatin, pitavastatin, and rifampicin were purchased from Bio-Connect (Huissen, The Netherlands). Rosuvastatin calcium, heparin, taurocholate, and insulin were purchased from Sigma-Aldrich Chemie B.V. (Zwijndrecht, The Netherlands). Atorvastatin lactone, 2-hydroxy atorvastatin, 2-hydroxy atorvastatin lactone, 4-hydroxy atorvastatin, and 4-hydroxy atorvastatin lactone were obtained from Toronto Research Chemicals (Toronto, ON, Canada). Epoprostenol was purchased from R\&D Systems (Minneapolis, MN). Vitamin solution, L-glutamine, Minimum Essential Medium (MEM) essential acids, and glutamax were obtained from Gibco (Paisley, Scotland). Calcium gluconate $10 \%$ was obtained from Pharmamarket (Hove, Belgium).

Porcine Livers. Livers were obtained from a local slaughterhouse (Sus scrofa domesticus, approximately at the age of 6 months, with body weight between 100 and $120 \mathrm{~kg}$ ). Pigs were sacrificed by a standardized procedure of electrocution followed by exsanguination. Thereafter, $3 \mathrm{~L}$ of blood was collected in a container supplemented with 25,000 IU of heparin. All abdominal organs were dissected outside the animal and collected. Within 20 minutes after termination, the vena porta was cannulated and directly flushed by gravity with $3 \mathrm{~L}$ of $\mathrm{NaCl}$ 0.9\% (Baxter BV, Utrecht, The Netherlands) supplemented with $5000 \mathrm{IU}$ of heparin followed by $2 \mathrm{~L}$ of ice-cold histidine-tryptophan-ketoglutarate solution (Plegistore, Warszawa, Poland). In the meantime, the arteria hepatica was dissected, cannulated, and subsequently flushed with histidine-tryptophan-ketoglutarate. At the laboratory, side branches were ligated, and the common bile duct was cannulated, whereas the ductus cysticus, derived from the gall bladder, was ligated.

Normothermic Machine Perfusion. The porcine livers were perfused using the LiverAssist device (Organ Assist, Groningen, The Netherlands). The machine consists of two rotary pumps that provide a pulsatile flow to the hepatic artery and a continuous flow to the portal vein. The system was filled with $2 \mathrm{~L}$ perfusion fluid containing red blood cells and plasma (Supplemental Table 1). Insulin, taurocholate, heparin, and epoprostenol were provided as continuous infusion at a rate of $10 \mathrm{U} / \mathrm{h}, 1041 \mathrm{U} / \mathrm{h}, 10 \mathrm{ml} / \mathrm{h}(2 \% \mathrm{w} / \mathrm{v})$, and $8 \mu \mathrm{g} / \mathrm{h}$, respectively, to maintain liver functioning including bile flow. Additionally, amino acids and vitamins were continuously provided to keep the liver metabolically active (Supplemental Table 1). Gas delivery to the LiverAssist consisted of $95 \%$ oxygen and $5 \%$ carbon dioxide at $2 \mathrm{~L} / \mathrm{min}$, and the temperature was set at $39^{\circ} \mathrm{C}$ (body temperature pigs). The livers were perfused with a portal pressure of $11 \mathrm{mmHg}$ and a mean arterial pressure of $50 \mathrm{mmHg}$. Upon perfusion, additional boluses of sodium bicarbonate and glucose were applied depending on perfusate $\mathrm{pH}$ (range 7.357.45 ) and glucose concentration $(>5 \mathrm{mmol} / \mathrm{l})$. Arterial blood gas samples were taken hourly to monitor liver viability ( $\mathrm{pH}$, glucose, $\mathrm{Na}, \mathrm{K}$, lactate, etc.) using the i-STAT clinical analyzer (Abbot Point of Care Inc., Princeton, NJ).

Drug Administration during Perfusion. The plasma and biliary concentration of atorvastatin, rosuvastatin, and pitavastatin and rifampicin were determined. Additionally, atorvastatin metabolite formation was determined. The statins and rifampicin were selected based on clinically known DDI and in vitro transporter study data and are presented in Table 1. Initial portal doses for atorvastatin and rifampicin applied to the system were based on simulations by SimCyp. After pilot experiments, the doses were increased $2 \times$ for atorvastatin $(0.052 \mathrm{mg}$ to $0.104 \mathrm{mg})$ and $3 \times$ for rifampicin $(22.6-67.7 \mathrm{mg})$ to facilitate proper detection by LC/MS. For the other two statins, rosuvastatin and pitavastatin, the compound profiles were not available in SimCyp. Therefore, the portal doses of rosuvastatin and pitavastatin were based on the oral dosage and corrected for the fraction absorbed, average correction for fraction escaping the gut (0.7) (Varma et al., 2010), and corrected for the total circulating volume of $2 \mathrm{~L}$ in the perfusion system (compared with $5 \mathrm{~L}$ in vivo). To study DDI, the setup as depicted in Fig. 1 was applied. After a stabilization period of 120 minutes, the statin was administered as a slow bolus at a rate of $1 \mathrm{ml} / \mathrm{min}$ during 10 minutes to the portal vein. Time of starting the slow bolus was set at $\mathrm{t}=0$ minutes. Subsequently, plasma and bile samples were taken for the following 120 minutes. Arterial blood samples were taken at $\mathrm{t}=0,2,4,6,8,10,15,20,30,40,50,60$, 90, and 120 minutes. Portal samples were taken during the administration of the drug at $\mathrm{t}=5$ and $\mathrm{t}=10$ minutes to determine the first-pass effect. This portal sampling point was $\sim 30 \mathrm{~cm}$ from the portal dosing point. Bile samples were collected in 10-minute fractions. Blood samples were centrifuged directly after collection at $1.3 \mathrm{~g}$ for 10 minutes at $4^{\circ} \mathrm{C}$, and thereafter plasma (and bile) samples were immediately stored at $\leq-70^{\circ} \mathrm{C}$ until further processing. Drug concentrations in plasma, bile, and liver biopsies were determined by LC-MS/MS analysis 
TABLE 1

General properties on statins and rifampicin as perpetrator drug

Oral doses (in milligrams) applied in vivo, fraction absorbed, and bolus applied to the portal vein of ex vivo perfused livers (in milligrams).

\begin{tabular}{|c|c|c|c|c|c|}
\hline Substrate (Victim Drug) & Transporters Involved & Metabolism & Fraction Absorbed & Oral Doses & Bolus Applied to Ex Vivo Liver \\
\hline & & & $\%$ & & $m g$ \\
\hline Atorvastatin & $\begin{array}{l}\text { NTCP, OATP1B1, OATP1B3, and } \\
\text { OATP2B1 } 1^{\mathrm{a}, \mathrm{b}}\end{array}$ & CYP3A4 $4^{\mathrm{a}, \mathrm{b}}$ & $12^{\mathrm{c}}$ & $10^{\mathrm{g}}$ & 0.104 \\
\hline Rosuvastatin & $\begin{array}{l}\text { OATP1B1, OATP1B3, NTCP, MRP2, } \\
\text { and BCRP }\end{array}$ & CYP2C $9^{d}$ & $50^{\mathrm{e}}$ & $10^{\mathrm{h}}$ & 1.400 \\
\hline $\begin{array}{l}\text { Perpetrator drug } \\
\text { Rifampicin }\end{array}$ & & & $95^{\mathrm{f}}$ & $600^{\mathrm{a}, \mathrm{b}}$ & 67.7 \\
\hline
\end{tabular}

${ }^{a}$ Takehara et al. (2018).

${ }^{b}$ Mori et al. (2019).

${ }^{c}$ Mukhtar et al. (2005)

${ }^{d}$ Schneck et al. (2004)

${ }^{e}$ Sjöberg et al. (2013).

${ }^{f}$ Zwolska et al. (1998)

${ }^{8}$ Lennernäs (2003).

${ }^{h}$ Bergman et al. (2006).

as described below. At 120 minutes, biopsies were taken $(n=2)$ to determine the intracellular concentration in the hepatocytes. After the first 120 minutes, a slow bolus at 10 minutes $(1 \mathrm{ml} / \mathrm{min})$ of $67.7 \mathrm{mg}$ rifampicin was administered to the liver, and after 5 minutes $(t=125$ minutes), a subsequent slow bolus of the statin was administered to the portal vein of the liver. The same sampling schedule for the following 120 minutes was applied. After the last sampling time point of the perfusion experiment, a biopsy was again taken from the liver to determine the intracellular concentration of the substrate and perpetrator. The biopsies were snap-frozen and immediately stored at $\leq-70^{\circ} \mathrm{C}$.

Bioanalysis. The concentration of atorvastatin and its metabolites, pitavastatin, rosuvastatin, and rifampicin in plasma and bile were quantified using LC/MS. Briefly, $20 \mu \mathrm{l}$ of sample was extracted by adding $100 \mu \mathrm{l}$ of acetonitrile containing internal standard. Samples were vortexed and centrifuged at $3000 \mathrm{rpm}$ for 5 minutes, and $100 \mu \mathrm{l}$ of supernatant was collected in a clean sample plate. Samples were then mixed with $50 \mu 1$ of water, vortexed, and injected into LC/MS for quantification. The details of LC/MS conditions used for the analysis of each compound are shown in Supplemental Table 2. The mass spectrometer (AB Sciex API 5500) was operated in electrospray positive ion mode with the capillary voltage of 5.5 $\mathrm{kV}$ and spray temperature of $550^{\circ} \mathrm{C}$. The multiple reaction monitoring transitions used for all the compounds are shown Supplemental Table 3.

Liver Function Assessment. During the perfusion experiment, blood gas analysis was executed every hour by measuring, among others, $\mathrm{pH}, \mathrm{pO}_{2}, \mathrm{pCO}_{2}$, $\mathrm{SO}_{2}$, glucose, and lactate concentrations using a blood gas analyzer (i-STAT Alinity, Abbott). Additionally, hepatic artery and portal vein flow and resistance values were reported from the LiverAssist machine.

Multiple parameters were measured in perfusate and bile samples from the perfused livers to study liver viability. Total bilirubin, alanine transaminase (ALT), and aspartate transaminase (AST) concentrations in the plasma and bile samples were measured using a Reflotron (Roche). Additionally, at the end of the perfusion period (360 minutes of perfusion), a bolus $(10 \mathrm{mg}$ ) of indocyanine green (ICG) was applied to the ex vivo liver to assess liver functionality by studying the clearance of ICG from the perfusate. Samples were taken at $\mathrm{t}=0$, $1,2,4,6,8,10,15,20,30,40,50$, and 60 minutes after dosing. Samples were centrifuged to obtain plasma, and thereafter, $100 \mu \mathrm{l}$ was sampled and measured at 788 emission and 813 excitation using a microplate reader (Tecan infinite m200 pro).

Liver perfusion studies were approved when the following acceptance criteria were met: 1) stable bile production and bile flow throughout the whole experiment with $>12 \mathrm{ml} / \mathrm{h}$ after 120 minutes of perfusion; 2) plasma bilirubin levels $<20 \mu \mathrm{mol} / \mathrm{L}$ after 120 minutes of perfusion; 3) bile bilirubin levels $>200 \mu \mathrm{mol} /$ $\mathrm{L}$ after 120 minutes of perfusion; 4) plateau phase of AST and ALT reached within 60 minutes of perfusion; 5) plasma ICG reduced by $50 \%$ within 40 minutes after administration of ICG, under rifampicin conditions.

In total, 13 livers were perfused for a period of 420 minutes. Of these livers, three perfusions were excluded from the PK analysis to study DDI: one liver exposed to atorvastatin was excluded because of an experimental dosing error (Supplemental Figs. 1 and 2), and two livers exposed to pitavastatin showed acute hepatotoxic effects. The PK data of these livers are shown in the supplemental figures (Supplemental Figs. 1 and 2).

Quantitative LC-MS/MS Analysis of Hepatic Transporters in Porcine and Human Livers. To study transporter and enzyme expression in porcine liver tissue compared with the expression in human liver tissue, tissue from five healthy domestic pigs (S. s. domesticus, two male and three female, age 10-14 weeks, and body weight between 15 and $25 \mathrm{~kg}$ ) was collected. These animals were additionally used for educational purposes at the Utrecht University (Utrecht, The Netherlands). The local animal welfare office approved the use of these animals for these purposes, which was in full compliance with the aim to contribute to the reduction, refinement, and replacement of animal experiments. Before termination, pigs had free access to food and water. Liver tissue of domestic pigs was collected only when defined healthy as judged by a veterinarian.

Human liver samples were derived from 15 individuals, of which five were anonymously collected at the University Medical Center of Groningen (Groningen, The Netherlands) and were kindly provided by Prof. Dr. G.M.M. Groothuis (University of Groningen, The Netherlands) and 10 were collected at the Department of Surgery, Uppsala University Hospital (Uppsala, Sweden), and were kindly provided by Prof. Dr. P. Artursson [seven male and three female donors; human liver specimens also used in previously published study (Wegler et al., 2017)]. Collection of redundant tissue from surgeries (collected as waste
Fig. 1. Schematic representation of the experimental setup. Livers were connected to the perfusion device, and after 120 minutes, a 10-minute bolus $(1 \mathrm{ml} / \mathrm{min})$ with a statin was administered to the liver. Plasma and bile samples were taken for 120 minutes. At $\mathrm{t}=120$, rifampicin was administered for 10 minutes at $1 \mathrm{ml} / \mathrm{min}$, and at $\mathrm{t}=125$, the second bolus of the statin was administered. Subsequently, plasma and bile samples were taken for the following 120 minutes.

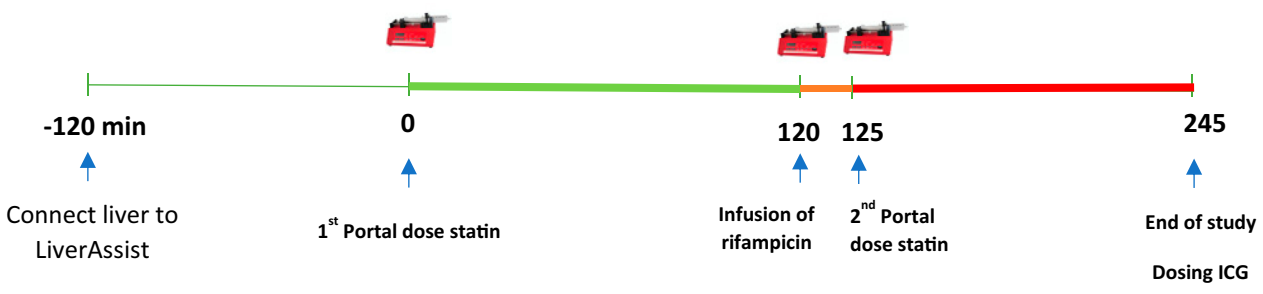


material) was approved by the Medical Ethical Committee of the University Medical Center of Groningen or the Uppsala Ethical Review Board (ethical approval number 2009/028 and 2011/037). No clinically relevant or identifiable information from the patients was collected.

To determine the protein levels of BCRP, BSEP, MDR1, MRP1, MRP2, OATP2B1, OCT1, GLUT1, MCT1, MRP3, NTCP, OATP1B1, and OATP1B3 in porcine and human liver tissue, we followed the protocol of membrane isolation and trypsin digestion as previously described for tissue samples and cell lines (Bosgra et al., 2014; Vaessen et al., 2017). All samples were processed in duplicate. LC-MS/MS settings were as previously described (Vaessen et al., 2017). For each peptide, three transitions were chosen (Q3-1, Q3-2, and Q3-3) for quantitation and confirmation (Supplemental Table 4). In case no suitable prototypic peptide could be selected for the human and porcine transporter proteins, two separate peptides were selected and synthesized (Supplemental Table 4). Peptides labeled with $15 \mathrm{~N}$ and $13 \mathrm{C}$ (AQUA peptide) were synthesized (Sigma-Aldrich Chemie, Steinheim, Germany) and used as an internal standard for quantification. For each peptide, a calibration curve of $0.01-50 \mathrm{ng} / \mathrm{ml}$ and quality controls were included in every run. Data are expressed as fentomoles transporter protein per milligram liver.

Data Analysis. Data obtained during the perfusion studies were analyzed using GraphPad Prism version 8. Values for the area under the concentration-time curve (AUC) were calculated using the linear trapezoidal method. The AUC ratio (AUCR) was determined by dividing the $\mathrm{AUC}_{120-240}$ minutes $/ \mathrm{AUC}_{0-120}$ minutes. Student's $t$ test was used to analyze differences between two groups.

\section{Results}

Assessment of Liver Functionality during Perfusion. During the perfusion of the livers, flow and bile production were monitored. The perfused livers ( $n=3$ for atorvastatin, $n=3$ for pitavastatin, and $n=4$ for rosuvastatin) included in the PK analysis showing a stable portal and arterial flow of $1548 \pm 229 \mathrm{ml} / \mathrm{min}$ and $175 \pm 67 \mathrm{ml} / \mathrm{min}$, respectively, and substantial bile production throughout the experiment (on average $79.2 \pm 27.6 \mathrm{ml}$ in a period of 360 minutes) (Supplemental Fig. 1). With $57.1 \pm 15.7 \mathrm{ml}$, the livers exposed to pitavastatin produced the least amount of bile during the total perfusion period. For atorvastatinand rosuvastatin-exposed livers, bile production was $78.9 \pm 24.7 \mathrm{ml}$ and $107.2 \pm 12.5 \mathrm{ml}$, respectively.

Plasma Concentration Profiles and Biliary Excretion of Atorvastatin, Pitavastatin, and Rosuvastatin. To study plasma and biliary clearance of the statins, atorvastatin $(0.104 \mathrm{mg})$, pitavastatin $(0.141$ $\mathrm{mg}$ ), or rosuvastatin $(1.400 \mathrm{mg}$ ) was administered via the portal vein in a slow bolus (10 minutes, $1 \mathrm{ml} / \mathrm{min})$, resulting in initial portal concentrations of $7.02 \mathrm{ng} / \mathrm{ml}, 8.50 \mathrm{ng} / \mathrm{ml}$, and $108.73 \mathrm{ng} / \mathrm{ml}$ for atorvastatin, pitavastatin, and rosuvastatin, respectively. During the dosing period and thereafter, multiple perfusate and bile samples were taken to assess the pharmacokinetic profile of the drugs. Sampling at the portal vein during the 10-minute dosing period, and simultaneously at the arterial side, enabled us to calculate the hepatic extraction ratio. Figure 2 and Table 2 show the plasma and biliary profile of the statins and plasma rifampicin concentration. The livers showed a hepatic extraction ratio of $0.8 \pm 0.1$ for all statins (Fig. 2, A, B, D, E, G, and H; Table 2). Within 10 minutes after the start of the bolus administration, atorvastatin was detected in the bile with a $\mathrm{T}_{\max }$ of $35.0 \pm 5.0$ minutes. A total of $13.0 \% \pm 5.6 \%$ of the parent compound was secreted into the bile within 120 minutes of perfusion. Pitavastatin secretion into the bile was slower and was detected in the bile 20 minutes after the start of the administration with a substantially lower total biliary excretion of $1.1 \%$ $\pm 0.1 \%$ within 120 minutes. Rosuvastatin was detected in the bile 10 minutes after the start of the administration, reaching peak levels at 22.5
A

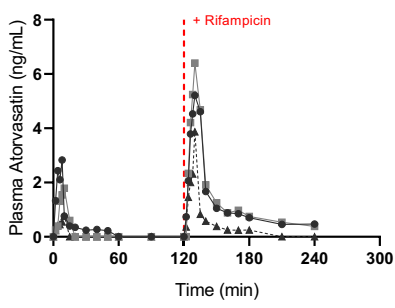

D

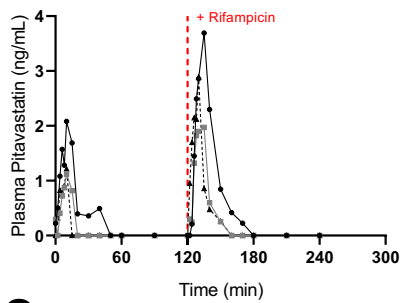

G

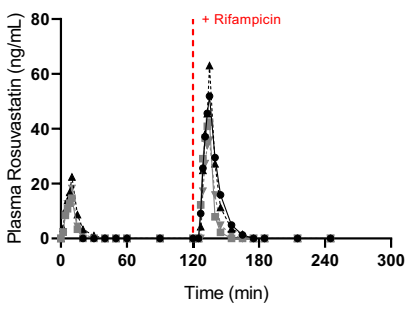

B

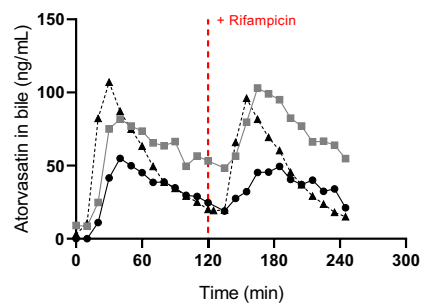

E

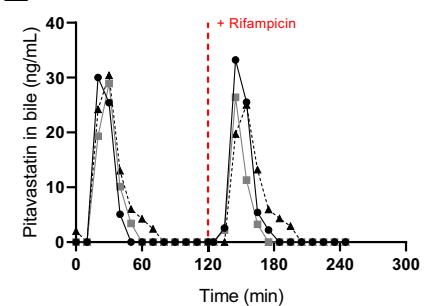

H

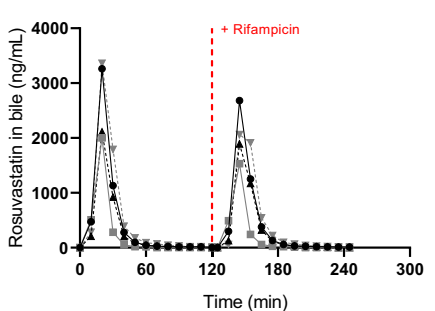

C

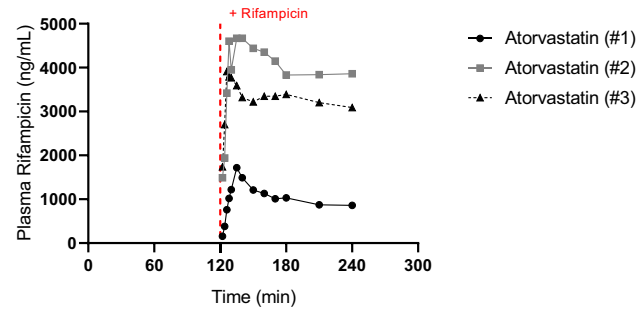

F

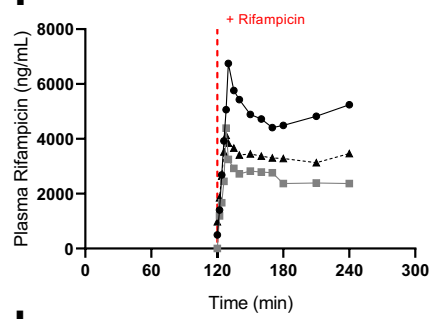

- Pitavastatin (\#1)

- Pitavastatin (\#2)

-.. Pitavastatin (\#3)

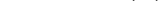

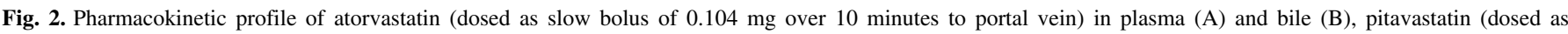

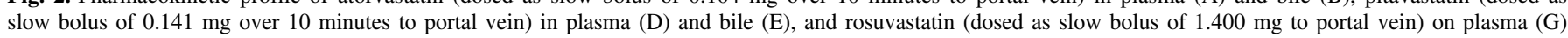
and bile $(\mathrm{H})$ Plasma pharmacokinetic profile of rifampicin (dosed as bolus of $67.7 \mathrm{mg}$ to the portal vein) shown for each experiment (C, F, and I). 


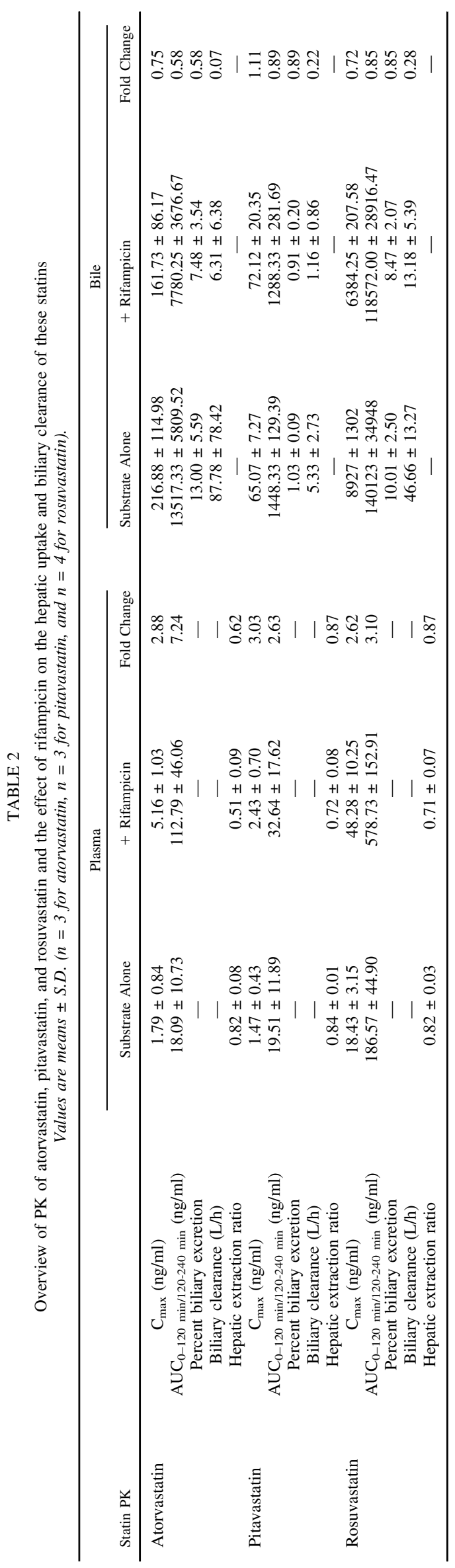

\pm 4.3 minutes. In total, $10.1 \% \pm 2.5 \%$ rosuvastatin was excreted into the bile during 120 minutes of perfusion.

Effect of Rifampicin on Statin Kinetics and Biliary Clearance. To study the effect of rifampicin on statin plasma kinetics and biliary clearance, a second bolus of the statin was coadministered with a bolus of rifampicin $(67.7 \mathrm{mg})$. Upon coadministration of rifampicin, the plasma $\mathrm{C}_{\max }$ increased $\sim 3$-fold for all statin drugs: from $1.8 \pm 0.8 \mathrm{ng}$ / $\mathrm{ml}$ to $5.2 \pm 1.1 \mathrm{ng} / \mathrm{ml}$ for atorvastatin, from $1.5 \pm 0.4 \mathrm{ng} / \mathrm{ml}$ to $4.5 \pm 1.9$ $\mathrm{ng} / \mathrm{ml}$ for pitavastatin, and from $18.4 \pm 3.2 \mathrm{ng} / \mathrm{ml}$ to $48.3 \pm 10.3 \mathrm{ng} / \mathrm{ml}$ for rosuvastatin (Fig. 2; Table 2). Additionally, all plasma AUCs of the statins increased upon coadministration of rifampicin: livers exposed to atorvastatin showed the highest AUCR of 7.2, followed by rosuvastatin (AUCR 3.1) and pitavastatin (AUCR 2.6) upon rifampicin coadministration (Fig. 3A). In line with these data, the most profound effect of rifampicin on the hepatic extraction was also observed for atorvastatin, decreasing from $0.8 \pm 0.1$ to $0.5 \pm 0.1$, whereas it decreased from $0.8 \pm$ 0.1 to $0.7 \pm 0.1$ for both pitavastatin and rosuvastatin. The addition of rifampicin resulted in a biliary secretion of $6.80 \% \pm 3.85 \%$ of administered atorvastatin, corresponding to 0.47 -fold reduction in biliary clearance. Interestingly, a more profound reduction in biliary excretion was observed for rosuvastatin and pitavastatin upon coadministration with rifampicin, i.e., 0.15 -fold and 0.11 -fold, respectively.

Pharmacokinetics of Rifampicin. Figure 2, C, F, and I show the concentration time profile of the perpetrator rifampicin in the three statin groups. The livers exposed to atorvastatin showed the lowest $\mathrm{C}_{\max }: 3.4$ $\pm 1.3 \mu \mathrm{g} / \mathrm{ml}$ for rifampicin compared with livers exposed to pitavastatin $(5.1 \pm 1.2 \mu \mathrm{g} / \mathrm{ml})$ and rosuvastatin $(5.3 \pm 1.0 \mu \mathrm{g} / \mathrm{ml}$; Fig. $2, \mathrm{C}, \mathrm{F}$, and I; Table 3). After administration, rifampicin was rapidly detected in the bile with a $\mathrm{T}_{\max }$ of $46.7 \pm 4.7$ minutes, $30.0 \pm 0.0$ minutes, and $35.0 \pm$ 11.2 minutes for livers exposed to atorvastatin, pitavastatin, and rosuvastatin, respectively. The biliary clearance of rifampicin was $6.7 \% \pm$ $4.8 \%, 5.7 \% \pm 2.5 \%$, and $10.9 \% \pm 1.6 \%$, respectively, in livers treated with atorvastatin, pitavastatin, and rosuvastatin livers.

Metabolism of Atorvastatin and the Effect of Rifampicin on Metabolism. Since atorvastatin is subjected to CYP3A4-mediated hepatic metabolism, we also investigated the presence of its known metabolites (atorvastatin lactone, 2-OH atorvastatin, 2-OH atorvastatin lactone, 4-OH atorvastatin, and $4-\mathrm{OH}$ atorvastatin lactone) in plasma and bile samples obtained from the perfused livers exposed to atorvastatin (Fig. 4; Table 3). All five clinically known metabolites were detected in the bile, but no metabolites were detected in plasma. For all metabolites, the biliary secretion was decreased upon the coadministration of rifampicin (Table 4). Main inhibition was shown for the metabolites atorvastatin lactone (AUCR of 0.1 ), followed by 2-OH atorvastatin (AUCR of 0.8) and 4-OH atorvastatin (AUCR of 0.7).

Bilirubin as Potential Endogenous Biomarker for OATP Function. Total bilirubin levels were measured in plasma and bile samples of the perfused livers (Fig. 5), as bilirubin was recently recommended as an endogenous biomarker for OATP1B1/1B3 function (Fromm 2012; Chu et al., 2017). Rifampicin, an inhibitor of multiple transporters including OATP1B1/1B3, should therefore also block the (re)uptake of (glucuronidated) bilirubin from the plasma. During the first 120 minutes of perfusion, when only the statins were administered to the livers, a stable concentration of plasma bilirubin was measured (Fig. 5A). Upon rifampicin exposure (120-240 minutes of perfusion), an increase in total plasma bilirubin was measured in all livers. For all three statins, the $\mathrm{AUC}_{120-240} / \mathrm{AUC}_{0-120}$ ratio showed a mean ratio of 1.6, indicating interference of rifampicin on the hepatic uptake of (glucuronidated) bilirubin. Total bilirubin concentration in the bile decreased upon rifampicin exposure, and a mean AUCR of $0.5 \pm 0.14$ was measured (Fig. 5B). 
A

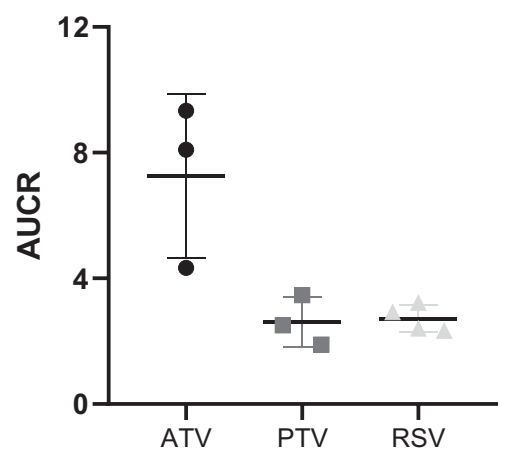

B

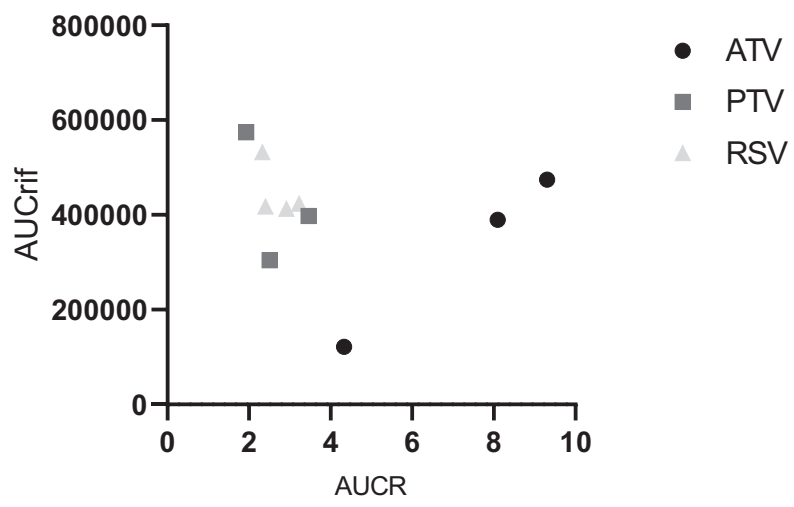

Fig. 3. (A) Showing the rank order of DDI in AUCR for atorvastatin (ATV), pitavastatin (PTV), and rosuvastatin (RSV). (B) Relation of AUCR to $\mathrm{AUC}_{\text {rifampicin. }}$.
First Signs of Drug-Induced Toxicity by Pitavastatin. Two out of five livers exposed to pitavastatin coadministered with rifampicin were excluded from the PK analysis. Compared with the other three livers exposed to pitavastatin, these two livers demonstrated a delay in plasma clearance of pitavastatin and rifampicin, with a plasma AUCR of 19.8 and 11.8 after the second bolus of pitavastatin (Fig. 6, A and C) and a lower hepatic extraction ratio of 0.5 for both affected livers (Fig. $6 \mathrm{H})$. Immediately after the second administration of pitavastatin, a reduction in the bile flow was observed for these two livers, and the bile production completely stopped after 360 minutes of perfusion (Fig. $6 \mathrm{G})$. Upon the addition of rifampicin, these same livers showed an increase in plasma bilirubin compared with all the other perfused livers $(60.1 \mu \mathrm{mol} / \mathrm{L}$ and $62.9 \mu \mathrm{mol} / \mathrm{L}$ at 360 minutes of perfusion) compared with the atorvastatin and rosuvastatin perfused livers $(23.2 \pm 7.4 \mu \mathrm{mol} /$ $\mathrm{L}$ at 360 minutes of perfusion) (Fig. 6D). Plasma rifampicin concentrations were also elevated compared with the other livers exposed to pitavastatin (Fig. 6C). To verify liver toxicity, plasma alanine aminotransferase (ALT) and AST levels were assessed (Fig. 6, E and F). The two livers showed increasing AST levels, indicating induced liver toxicity. No effect on ALT was measured, as all livers showed stable ALT levels, reaching a plateau phase after 60 minutes (Fig. 6F). Altogether, these results indicate a potential (start of) pitavastatininduced hepatotoxicity in the form of impaired drug and bilirubin clearance and compromised bile production.

Protein Expression of Hepatic Transporters. Figure 7 and Supplemental Table 5 show the absolute expression of drug transporters in liver tissue of porcine (domestic pig) and human origin. Although the expression of the main transporter proteins BCRP, MDR1, MRP1, MRP2, GLUT1, and MCT1 was similarly abundant in porcine and human livers, the expression of OCT1 was approximately 1.8-fold higher in human livers compared with porcine livers $(P<0.001)$. In contrast, the expression of BSEP, MRP3, NTCP, and OATP2B1 was 1.9-, 1.7-, 1.7-, and 2.6-fold higher, respectively, in porcine livers than in human livers $(P<0.01)$. OATP1B4 is the porcine ortholog for OATP1B1 and OATP1B3. The expression of OATP1B1 and OATP1B3 in human liver together was significantly lower $(P<0.05)$ than the protein expression level of OATP1B4 in porcine livers $(2.8 \pm 1.0 \mathrm{fmol} / \mathrm{mg}$ tissue in human livers; $5.8 \pm 1.8 \mathrm{fmol} / \mathrm{mg}$ tissue in porcine liver).

\section{Discussion}

The ability to study the biliary excretion and intracellular concentrations provides valuable information regarding metabolism and excretion of the drug. Thus far, to predict the hepatobiliary disposition of drugs, experimental studies have been performed using sandwich-cultured hepatocytes, isolated perfused organ systems with rat livers, or cannulated animal studies. In this study, we perfused porcine livers using a novel advanced pressure-driven perfusion machine with a red blood cell-based perfusate that is suitable for normothermic and oxygenated conditions (Borie et al., 2001; Boehnert et al., 2013; Watson et al., 2017). We describe for the first time the use of NMP of porcine livers to predict human hepatobiliary disposition and DDI of drugs as demonstrated by using known OATP substrate drugs such as atorvastatin, pitavastatin, and rosuvastatin with known OATP inhibitor rifampicin as a perpetrator drug. Hepatobiliary toxicity in humans is poorly predicted from animal studies, primarily due to the fact that many animals differ markedly from humans in response to pharmacological agents (Helke and Swindle, 2013). In contrast to dogs, mice, and rats, there is not much data on pigs in preclinical testing. Nevertheless, for more complex research questions, ex vivo models from pig origin are regularly used to study

TABLE 3

Overview of PK of rifampicin during ex vivo liver perfusion

Values are means \pm S.D. ( $n=3$ for atorvastatin, $n=3$ for pitavastatin, and $n=4$ for rosuvastatin $)$.

\begin{tabular}{|c|c|c|c|}
\hline & & Plasma & Bile \\
\hline \multirow[t]{4}{*}{ Atorvastatin } & $\mathrm{C}_{\max }(\mu \mathrm{g} / \mathrm{ml})$ & $3.43 \pm 1.25$ & $63.27 \pm 31.08$ \\
\hline & $\mathrm{T}_{\max }(\min )$ & $15.33 \pm 3.68$ & $46.67 \pm 4.71$ \\
\hline & $\operatorname{AUC}_{120-240 \min }(\mu \mathrm{g} / \mathrm{ml})$ & $328.58 \pm 150.18$ & $5622.59 \pm 2934.09$ \\
\hline & Percent biliary excretion & - & $8.39 \pm 4.38$ \\
\hline \multirow[t]{4}{*}{ Pitavastatin } & $\mathrm{C}_{\max }(\mu \mathrm{g} / \mathrm{ml})$ & $5.09 \pm 1.18$ & $64.96 \pm 1.92$ \\
\hline & $\mathrm{T}_{\max }(\min )$ & $10.33 \pm 2.05$ & $30.00 \pm 0.00$ \\
\hline & $\mathrm{AUC}_{120-240 \min }(\mu \mathrm{g} / \mathrm{ml})$ & $425.32 \pm 111.98$ & $4690.66 \pm 1066.66$ \\
\hline & Percent biliary excretion & - & $7.00 \pm 1.59$ \\
\hline \multirow[t]{4}{*}{ Rosuvastatin } & $\mathrm{C}_{\max }(\mu \mathrm{g} / \mathrm{ml})$ & $5.53 \pm 0.95$ & $88.18 \pm 7.56$ \\
\hline & $\mathrm{T}_{\max }(\min )$ & $12.00 \pm 1.00$ & $35.00 \pm 11.20$ \\
\hline & $\mathrm{AUC}_{120-240 \min }(\mu \mathrm{g} / \mathrm{ml})$ & $446.61 \pm 49.48$ & $7284.19 \pm 1053.33$ \\
\hline & Percent biliary excretion & - & $10.87 \pm 1.57$ \\
\hline
\end{tabular}


Fig. 4. Atorvastatin metabolite excretion into the bile $(n=1)$ upon dosing atorvastatin $(0.104 \mathrm{mg})$ to the portal vein of perfused porcine liver before (0-120 minutes) and after coadministration with perpetrator rifampicin (125-245 minutes).

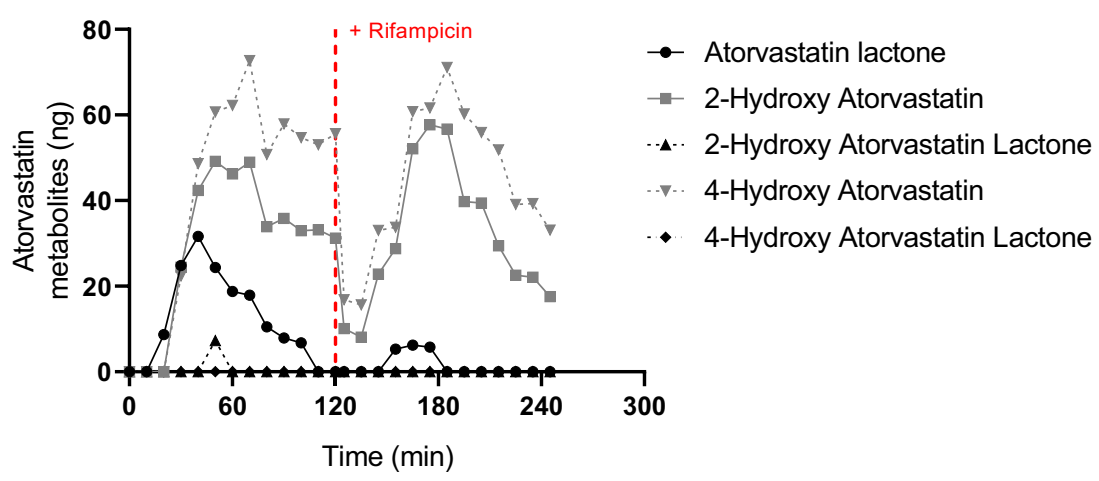

intestinal absorption or the hepatic and biliary disposition of drugs (Kararli, 1995; Anzenbacher et al., 1998; Bergman et al., 2009; Westerhout et al., 2014; Stevens et al., 2019). In a comprehensive overview, Vaessen and coworkers provided the protein and mRNA expression in human and pig intestinal tissues for a variety of transporters and enzymes. In general, the protein and mRNA expression were well comparable between humans and pigs (Vaessen et al., 2017). Furthermore, Elmorsi and coworkers recently showed a proteomic characterization of drug-metabolizing enzymes and transporters in the pig liver showing the high resemblance with humans (Elmorsi et al., 2020). These data on transporters are in line with the proteomic data we show here comparing transporter protein expression in pig livers to the expression in human liver tissue. Except for the expression of BSEP, MRP3, NTCP, OATP2B1, and OCT1, no significant differences were observed in the expression of other transporter proteins. There is no porcine homolog for the human OATP1B1; however, porcine livers were shown to express OATP1B4, which is the homolog of OATP1B3, showing $84 \%$ similarity (Dalgaard 2015; Elmorsi et al., 2020). Although an almost 2fold difference in human OATP1B1/1B3 versus pig OATP1B4 protein expression was observed, the obtained AUCRs were comparable to the human in vivo condition. Despite these differences, we here provide evidence that AUCR can be predicted by making use of ex vivo porcine NMP. The compounds tested are very good OATP (and NTCP) substrates, and the results suggest that the hepatic uptake contributes to a similar percentage to the total clearance in human and pigs. Other factors such as permeability differences between species and Km differences (for OATP-mediated uptake transporters) may compensate for the protein expression differences.

For this study, three statins were selected to study transporter-mediated DDI at the hepatic level. These statins (atorvastatin, rosuvastatin, and pitavastatin) are listed as clinical substrates for the assessment of OATP1B1 and OATP1B3 (Takehara et al., 2018). Additionally, the clearance of these drugs is mediated via diverse mechanism: CYP3A4 and OATP for atorvastatin, MRP2 and BCRP for rosuvastatin, and BCRP for pitavastatin. All three statins were shown to be good substrates for the uptake transporters, since a hepatic extraction ratio of $>0.7$ was observed. This is in line with clinically observed data
(Bergman et al., 2006; Elsby et al., 2012) demonstrating that the experimental setup is sufficient to predict the hepatic extraction ratio in humans.

In previous studies, statins have been applied to several preclinical models to predict rifampicin-induced DDI. Bergman et al. (2006) performed an in vivo human study in which rosuvastatin was administered into the jejunum via a Loc-I-Gut-catheter. The biliary clearance of rosuvastatin was measured after intestinal administration (Bergman et al., 2006). The $C_{\max }$ of rosuvastatin was detected 40 minutes after administration with a total biliary secretion of $11 \%$; these data correspond very well to that from our experiments, showing a biliary secretion of $10 \%$. Using the IPRL model, Lau et al. studied the interplay between transporters and enzymes in the disposition of atorvastatin (Lau et al., 2006a). Compared with our porcine perfusion model, the IPRL model showed an extensively reduced interaction between atorvastatin and rifampicin. The biliary secretion in the IPRL model of atorvastatin was $7.4 \%$, whereas in our model the biliary clearance was $13.0 \% \pm 5.6 \%$. Also, the effect of rifampicin on the inhibition of the biliary clearance was remarkably lower ( $21 \%$ in the IPRL versus $50 \%$ in our model). The IPRL may therefore underpredict the DDI for atorvastatin and rifampicin. Together, these data show the IPRL model underpredicts the biliary clearance, whereas a good comparability is observed between the porcine and human in vivo situation to the ex vivo perfused pig liver model. The metabolic activity of porcine livers during perfusion was shown by the presence of five different atorvastatin metabolites in the bile. The presence of all these metabolites in our study indicates that CYP3A4, CYP2C8, and UGT1A3 are metabolically active in the perfused pig liver (Lau et al., 2006b, 2007; Riedmaier et al., 2011).

In the experiments with atorvastatin, variability in AUCR was observed between replicates. Although rifampicin was administered in a similar slow bolus in each experiment, variability in plasma rifampicin concentrations were observed, possibly due to experimental handling and difference in total perfusate volume. Additionally, in clinical studies, the highest variation in AUCR is also observed for atorvastatin compared with the pitavastatin and rosuvastatin groups (Prueksaritanont et al., 2017; Takehara et al., 2018; Mori et al., 2019). Our results showed a relation between plasma rifampicin AUC and AUCR for atorvastatin, whereas minor variation was observed for the pitavastatin and

TABLE 4

Percent biliary excretion of atorvastatin $(0.104 \mathrm{mg})$ metabolites for atorvastatin alone and atorvastatin + rifampicin $(n=1)$

\begin{tabular}{|c|c|c|c|}
\hline Percent Biliary Clearance of Metabolites & Atorvastatin & Atorvastatin + Rifampicin & AUCR \\
\hline Atorvastatin lactone & 1.45 & 0.17 & 0.11 \\
\hline 2-Hydroxy atorvastatin & 3.49 & 2.64 & 0.76 \\
\hline 2-Hydroxy atorva lactone & 0.07 & 0.00 & 0.00 \\
\hline 4-Hydroxy atorvastatin & 4.91 & 3.33 & 0.68 \\
\hline 4-Hydroxy atorvastatin lactone & 0.00 & 0.00 & 0.00 \\
\hline
\end{tabular}



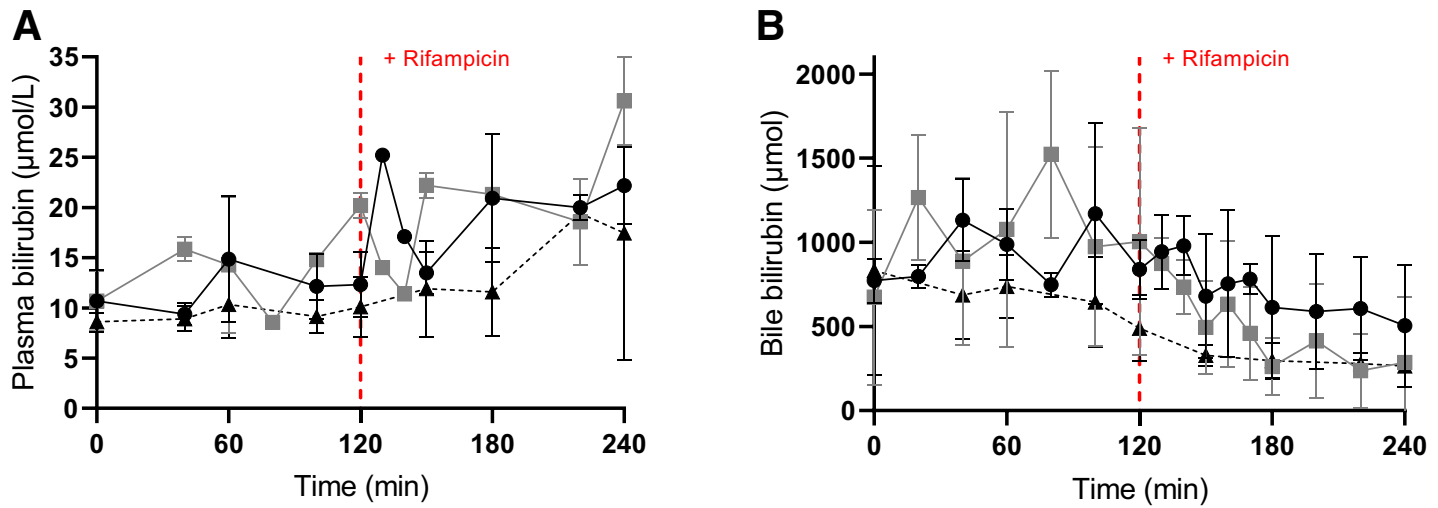

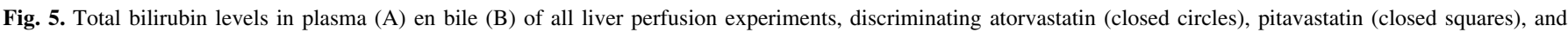
rosuvastatin (closed triangles), before (0-120 minutes) and after coadministration with perpetrator rifampicin (125-245 minutes).

rosuvastatin group (Fig. 3B). A comparable concentration-dependent inhibition effect of rifampicin on atorvastatin clearance was previously shown in vivo by Takehara et al. (2018) and Mori et al. (2019) and in vitro by Lau et al. (2006a). Upon coadministration with rifampicin, the most profound effect was observed for atorvastatin (AUCR of 7.24), followed by rosuvastatin (AUCR of 3.07) and pitavastatin (AUCR of 3.03). As can be observed in Table 5, this same absolute AUCR as well as rank order of DDI magnitude was observed in studies with healthy
A

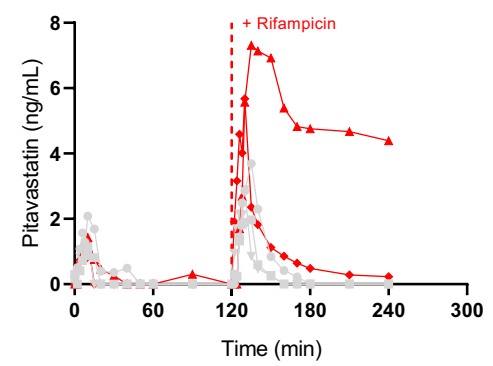

D

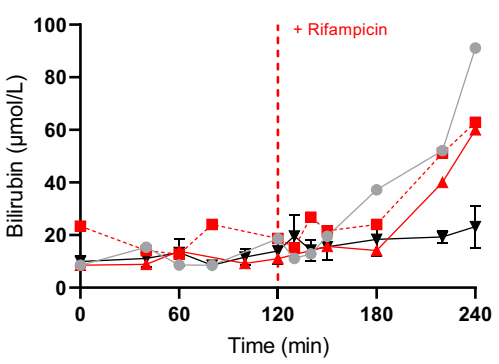

G

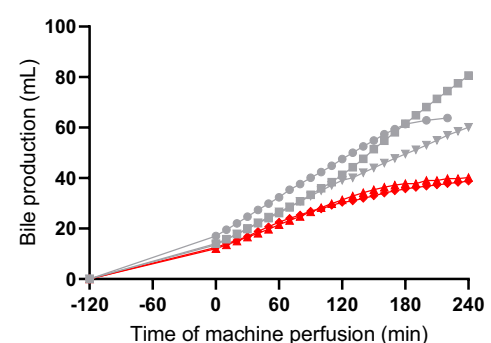

B

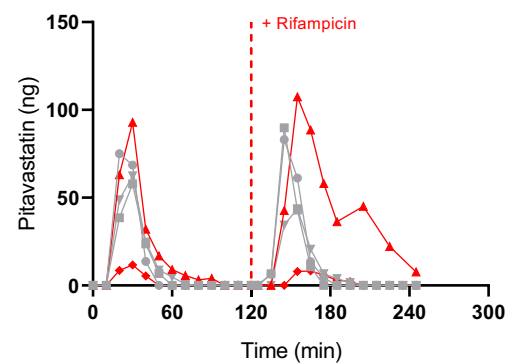

E

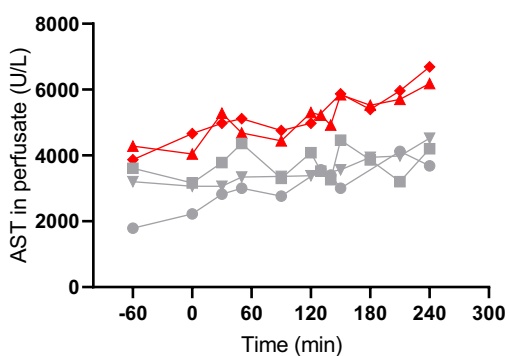

H

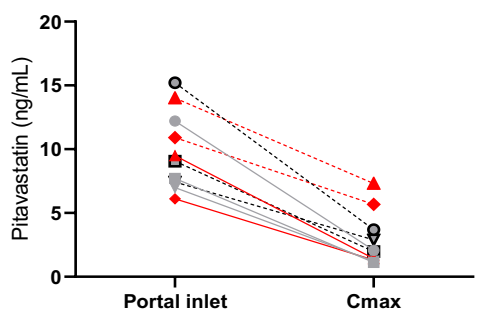

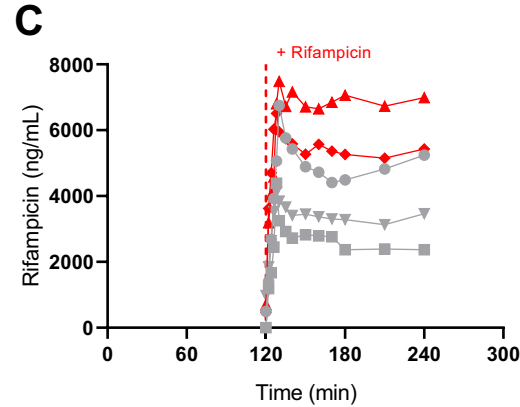

$\mathbf{F}$

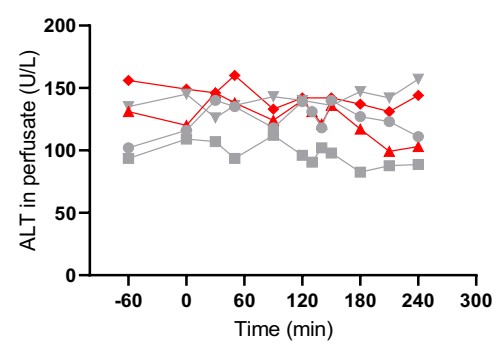

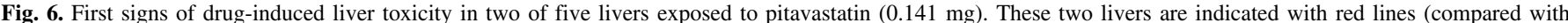

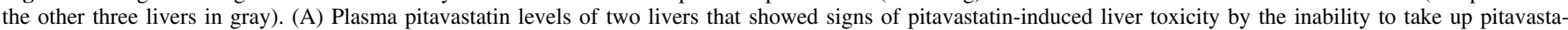

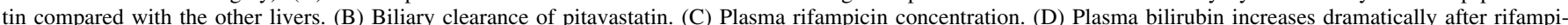

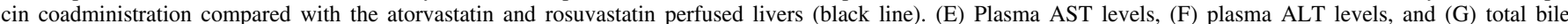
production during 360 minutes of perfusion. (H) Hepatic extraction during dosing ex vivo perfused livers (dotted lined represents the coadministration of rifampicin). 
Fig. 7. Absolute expression ( $\mathrm{fmol} / \mathrm{mg}$ tissue) of various uptake and efflux transporter proteins within the plasma membrane of porcine livers $(n=5)$ compared with the protein expression in human liver $(n=15)$. Significant differences are denoted as asterisks (Student's $t$ test $* P<0.05$, $* * P<0.01, * * * P<0.001)$

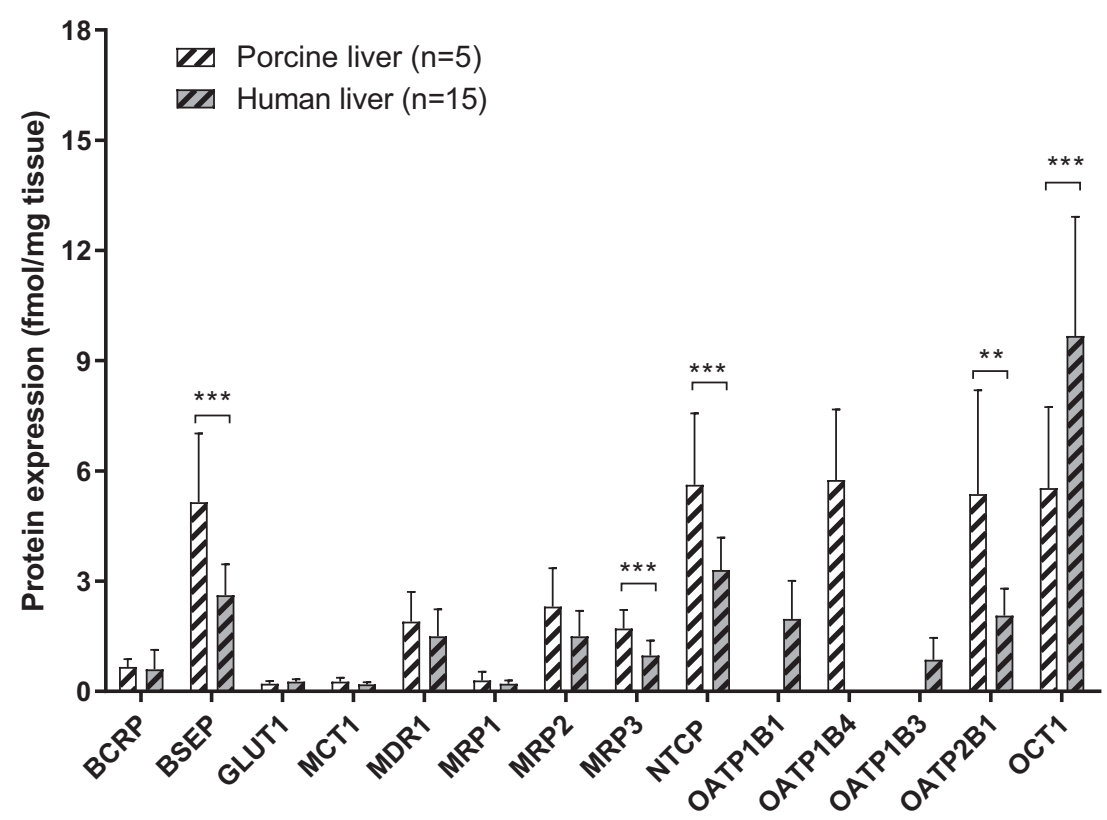

volunteers (Prueksaritanont et al., 2017; Takehara et al., 2018; Mori et al., 2019).

In this study, pitavastatin exposure was shown to affect hepatic function in two out of five perfused livers. Pitavastatin is one of the least prescribed statins (Amiri, 2020), and although there are infrequent cases known of pitavastatin-induced liver injury, it is known that pitavastatin can increase plasma AST, ALT, and bilirubin concentration in the clinic (Teramoto et al., 2010; Thapar et al., 2013; Kumar et al., 2018; Bhatti and Tadi, 2020). Here, increased plasma AST was observed in two out of five livers exposed to pitavastatin. These same livers also showed the lowest bile production, the lowest bile bilirubin AUCR, the most profound effect on the hepatic extraction ratio, and a prolonged ICG half-life (Supplemental Fig. 3). Together, these results indicate first signs of acute drug-induced hepatoxicity. The therapeutic dose of pitavastatin is between 1 and $4 \mathrm{mg}$ daily. However, the Food and Drug Administration recommends not to exceed $2 \mathrm{mg}$ once daily when patients also take rifampicin. Rifampicin significantly increases the $\mathrm{C}_{\max }$ of pitavastatin and therefore also increases the risk of rhabdomyolysis and myopathy (https://www.accessdata.fda. gov/drugsatfda_docs/label/2019/022363s015lbl.pdf). In our study, the repeated dosing of pitavastatin could have resulted in hepatic injury due to affecting the ATP levels of the liver. Viola et al. (2012) showed a dramatic depletion of ATP in keratinocyte-irradiated cells that were exposed to pitavastatin. Since the uptake and excretion of pitavastatin, bilirubin, and rifampicin are ATP-dependent processes, depletion of ATP resulted in a deteriorated functioning of these processes. A decrease in ATP levels may result in apoptosis and eventually necrosis (Viola et al., 2012). This might be an explanation of our observations. To our knowledge, there is no other preclinical model that showed these acute adverse effects of pitavastatin in the liver.

Lately, the interest in endogenous biomarkers reflecting transporter involvement has increased. An example of such an endogenous biomarker is bilirubin. Because of the role of OATP1B1 and OATP1B3 in bilirubin uptake, bilirubin could serve as an endogenous biomarker for OATP1B1- and OATP1B3-related DDIs in the liver (Fromm, 2012; Chu et al., 2017). In our model, after administration of rifampicin, a direct increase in plasma bilirubin concentration was measured (AUCR 1.89), showing the direct inhibition of OATP-mediated hepatic uptake of (glucuronidated) bilirubin. Furthermore, a decrease in biliary total bilirubin concentration was measured after the addition of rifampicin, reflecting the inhibition of MRP2 and possibly UGT1A1. Unfortunately, no good correlation between plasma rifampicin concentration and plasma and bile bilirubin AUCR was observed, indicating that bilirubin fits more as a control marker rather than a precise biomarker. The current practice involves the use of coproporphyrin I and III (CP-I, CP-III), and conjugated bile salts as clinical biomarkers for OATPs (Mori et al., 2019). Therefore, studies should incorporate these suggested biomarkers upon assessing DDI potential of drugs.

Conclusion. In conclusion, we have demonstrated that NMP of porcine livers is a potential novel and reliable model to study OATP-mediated DDI and its effect on hepatic clearance, biliary excretion, and plasma (metabolite) profile of statins. Overall, the rank order of DDI severity indicated in our experiments is in good agreement with clinical data, with the lowest DDI for pitavastatin and the highest for atorvastatin, indicating the potential importance of this new ex vivo model in early drug discovery.

TABLE 5

Comparison of plasma AUCR between the NMP porcine liver model and in vivo studies In all three clinical studies, the statins were dosed as a cocktail in healthy volunteers.

\begin{tabular}{|c|c|c|c|c|}
\hline & NMP Porcine Liver Model (Current Study) & Mori et al., 2019 & Takehara et al., 2018 & Prueksaritanont et al., 2017 \\
\hline Atorvastatin & 7.24 & 7.29 & 6.1 & 10.01 \\
\hline Pitavastatin & 2.63 & 4.01 & 2.8 & 4.45 \\
\hline Rosuvastatin & 3.10 & 2.48 & 2.4 & 5.38 \\
\hline
\end{tabular}



Normothermic Machine Perfusion of Porcine Livers as Novel Preclinical Model to Study Drug-Drug Interaction of Atorva-
statin, Pitavastatin, and Rosuvastatin with Inhibitor Rifampicin

\section{Acknowledgments}

We thank Angelique Speulman-Saat, Lisanne Pieters, Amber Zeeman, and Mariska Gröllers-Mulderij for their excellent work in the laboratory and OrganAssist for their assistance. We thank Martin Paton of Takeda pharmaceutical Co. for his assistance with the bioanalytical assays.

\section{Authorshtions}

Participated in research design: Stevens, Zhu, Chothe, Chowdhury, van de Steeg.

Conducted experiments: Stevens.

Performed data analysis: Stevens, Zhu.

Wrote of contributed to the writing of the manuscript: Stevens, Zhu, Chothe, Chowdhury, Donkers, Vaes, Knibbe, Alwayn, van de Steeg.

\section{References}

Amiri M (2020) Worldwide statins prescription pattern: is it similar. Biom Biostat Int J. 9:194. Anzenbacher P, Soucek P, Anzenbacherová E, Gut I, Hrubý K, Svoboda Z, and Květina J (1998) Presence and activity of cytochrome P450 isoforms in minipig liver microsomes. Comparison with human liver samples. Drug Metab Dispos 26:56-59.

Bergman E, Forsell P, Tevell A, Persson EM, Hedeland M, Bondesson U, Knutson L, and Lennernäs H (2006) Biliary secretion of rosuvastatin and bile acids in humans during the absorption phase. Eur J Pharm Sci 29:205-214.

Bergman E, Lundahl A, Fridblom P, Hedeland M, Bondesson U, Knutson L, and Lennernäs H (2009) Enterohepatic disposition of rosuvastatin in pigs and the impact of concomitant dosing with cyclosporine and gemfibrozil. Drug Metab Dispos 37:2349-2358.

Bhatti $\mathrm{H}$ and Tadi P (2020) Pitavastatin, StatPearls. [Internet].

Boehnert MU, Yeung JC, Bazerbachi F, Knaak JM, Selzner N, McGilvray ID, Rotstein OD, Adeyi OA, Kandel SM, Rogalla P, et al. (2013) Normothermic acellular ex vivo liver perfusion reduces liver and bile duct injury of pig livers retrieved after cardiac death. Am J Transplant 13:1441-1449.

Borie DC, Eyraud D, Boleslawski E, Lemoine A, Sebagh M, Cramer DV, Roussi J, Imbert-Bismut F, Germain G, and Hannoun L (2001) Functional metabolic characteristics of intact pig liver during prolonged extracorporeal perfusion: potential for a unique biological liver-assist device. Transplantation 72:393-405.

Bosgra S, van de Steeg E, Vlaming ML, Verhoeckx KC, Huisman MT, Verwei M, and Wortelboe HM (2014) Predicting carrier-mediated hepatic disposition of rosuvastatin in man by scalin from individual transfected cell-lines in vitro using absolute transporter protein quantification and PBPK modeling. Eur J Pharm Sci 65:156-166.

Chu X, Bleasby K, and Evers R (2013) Species differences in drug transporters and implications for translating preclinical findings to humans. Expert Opin Drug Metab Toxicol 9:237-252.

Chu X, Chan GH, and Evers R (2017) Identification of endogenous biomarkers to predict the propensity of drug candidates to cause hepatic or renal transporter-mediated drug-drug interactions. J Pharm Sci 106:2357-2367.

Dalgaard L (2015) Comparison of minipig, dog, monkey and human drug metabolism and disposition. J Pharmacol Toxicol Methods 74:80-92.

Elmorsi Y, Al Feteisi H, Al-Majdoub ZM, Barber J, Rostami-Hodjegan A, and Achour B (2020) Proteomic characterisation of drug metabolising enzymes and drug transporters in pig liver. Xen obiotica 50:1208-1219.

Elsby R, Hilgendorf C, and Fenner K (2012) Understanding the critical disposition pathways of statins to assess drug-drug interaction risk during drug development: it's not just about OATP1B1. Clin Pharmacol Ther 92:584-598.

Eshmuminov D, Becker D, Bautista Borrego L, Hefti M, Schuler MJ, Hagedorn C, Muller X Mueller M, Onder C, Graf R, et al, (2020) An integrated perfusion machine preserves injured human livers for 1 week. Nat Biotechnol 38:189-198.

Fagerholm U (2008) Prediction of human pharmacokinetics-biliary and intestinal clearance and enterohepatic circulation. J Pharm Pharmacol 60:535-542.

Fromm MF (2012) Prediction of transporter-mediated drug-drug interactions using endogenous compounds. Clin Pharmacol Ther 92:546-548.

Gores GJ, Kost LJ, and LaRusso NF (1986) The isolated perfused rat liver: conceptual and practical considerations. Hepatology 6:511-517.

Guillouzo A (1998) Liver cell models in in vitro toxicology. Environ Health Perspect 106 (Supp 2):511-532.

Helke KL and Swindle MM (2013) Animal models of toxicology testing: the role of pigs. Expert Opin Drug Metab Toxicol 9:127-139.

Ito K, Iwatsubo T, Kanamitsu S, Ueda K, Suzuki H, and Sugiyama Y (1998) Prediction of pharmacokinetic alterations caused by drug-drug interactions: metabolic interaction in the liver Pharmacol Rev 50:387-412.

Kararli TT (1995) Comparison of the gastrointestinal anatomy, physiology, and biochemistry of humans and commonly used laboratory animals. Biopharm Drug Dispos 16:351-380.
Kumar P, Mangla B, and Singh S (2018) Pitavastatin: a potent drug. Int J Pharma Res Health Sci 6:2070-2074

Lau YY, Huang Y, Frassetto L, and Benet LZ (2007) effect of OATP1B transporter inhibition on the pharmacokinetics of atorvastatin in healthy volunteers. Clin Pharmacol Ther 81:194-204.

Lau YY, Okochi H, Huang Y, and Benet LZ (2006a) Multiple transporters affect the disposition of atorvastatin and its two active hydroxy metabolites: application of in vitro and ex situ systems. $J$ Pharmacol Exp Ther 316:762-771.

Lau YY, Okochi H, Huang Y, and Benet LZ (2006b) Pharmacokinetics of atorvastatin and its hydroxy metabolites in rats and the effects of concomitant rifampicin single doses: relevance of first-pass effect from hepatic uptake transporters, and intestinal and hepatic metabolism. Drug Metab Dispos 34:1175-1181

Lennernäs H (2003) Clinical pharmacokinetics of atorvastatin. Clin Pharmacokinet 42:1141-1160. Mori D, Kashihara Y, Yoshikado T, Kimura M, Hirota T, Matsuki S, Maeda K, Irie S, Ieiri I, Sugiyama Y, et al. (2019) Effect of OATP1B1 genotypes on plasma concentrations of endogenous OATP1B1 substrates and drugs, and their association in healthy volunteers. Drug Metab Pharmacokinet 34:78-86.

Mukhtar RY, Reid J, and Reckless JP (2005) Pitavastatin. Int J Clin Pract 59:239-252.

Prueksaritanont T, Tatosian DA, Chu X, Railkar R, Evers R, Chavez-Eng C, Lutz R, Zeng W, Yabut J, Chan GH, et al. (2017) Validation of a microdose probe drug cocktail for clinical drug interaction assessments for drug transporters and CYP3A. Clin Pharmacol Ther 101:519-530.

Riedmaier S, Klein K, Winter S, Hofmann U, Schwab M, and Zanger UM (2011) Paraoxonase (PON1 and PON3) polymorphisms: impact on liver expression and atorvastatin-lactone hydrolysis. Front Pharmacol 2:41.

Schneck DW, Birmingham BK, Zalikowski JA, Mitchell PD, Wang Y, Martin PD, Lasseter KC, Brown CD, Windass AS, and Raza A (2004) The effect of gemfibrozil on the pharmacokinetics of rosuvastatin. Clin Pharmacol Ther 75:455-463.

Sjöberg A, Lutz M, Tannergren C, Wingolf C, Borde A, and Ungell A-L (2013) Comprehensive study on regional human intestinal permeability and prediction of fraction absorbed of drugs using the Ussing chamber technique. Eur J Pharm Sci 48:166-180.

Stevens LJ, Donkers JM, Dubbeld J, Vaes WHJ, Knibbe CAJ, Alwayn IPJ, and van de Steeg E (2020) Towards human ex vivo organ perfusion models to elucidate drug pharmacokinetics in health and disease. Drug Metab Rev 52:438-454.

Stevens LJ, van Lipzig MMH, Erpelinck SLA, Pronk A, van Gorp J, Wortelboer HM, and van de Steeg E (2019) A higher throughput and physiologically relevant two-compartmental human ex vivo intestinal tissue system for studying gastrointestinal processes. Eur J Pharm Sci 137:104989.

Takehara I, Yoshikado T, Ishigame K, Mori D, Furihata KI, Watanabe N, Ando O, Maeda K, Sugiyama Y, and Kusuhara H (2018) Comparative study of the dose-dependence of OATP1B inhibition by rifampicin using probe drugs and endogenous substrates in healthy volunteers. Pharm Res 35:138.

Teramoto T, Shimano H, Yokote K, and Urashima M (2010) New evidence on pitavastatin: efficacy and safety in clinical studies. Expert Opin Pharmacother 11:817-828.

Thapar M, Russo MW, and Bonkovsky HL (2013) Statins and liver injury. Gastroenterol Hepatol (N Y) 9:605-606.

Vaessen SF, van Lipzig MM, Pieters RH, Krul CA, Wortelboer HM, and van de Steeg E (2017) Regional expression levels of drug transporters and metabolizing enzymes along the pig and human intestinal tract and comparison with Caco-2 cells. Drug Metab Dispos 45:353-360.

Varma MV, Obach RS, Rotter C, Miller HR, Chang G, Steyn SJ, El-Kattan A, and Troutman MD (2010) Physicochemical space for optimum oral bioavailability: contribution of human intestinal absorption and first-pass elimination. J Med Chem 53:1098-1108.

Viola G, Grobelny P, Linardi MA, Salvador A, Dall'Acqua S, Sobotta Ł, Mielcarek J, Dall'Acqua F, Vedaldi D, and Basso G (2012) Pitavastatin, a new HMG-CoA reductase inhibitor, induces phototoxicity in human keratinocytes NCTC-2544 through the formation of benzophenanthridine-like photoproducts. Arch Toxicol 86:483-496.

Watson CJE, Kosmoliaptsis V, Randle LV, Gimson AE, Brais R, Klinck JR, Hamed M, Tsyben A, and Butler AJ (2017) Normothermic perfusion in the assessment and preservation of declined livers before transplantation: hyperoxia and vasoplegia-important lessons from the first 12 cases. Transplantation 101:1084-1098.

Wegler C, Gaugaz FZ, Andersson TB, Wiśniewski JR, Busch D, Gröer C, Oswald S, Norén A, Weiss F, Hammer HS, et al. (2017) Variability in mass spectrometry-based quantification of clinically relevant drug transporters and drug metabolizing enzymes. Mol Pharm 14:3142-3151.

Westerhout J, van de Steeg E, Grossouw D, Zeijdner EE, Krul CA, Verwei M, and Wortelboer HM (2014) A new approach to predict human intestinal absorption using porcine intestinal tissue and biorelevant matrices. Eur J Pharm Sci 63:167-177.

Yang X, Gandhi YA, Duignan DB, and Morris ME (2009) Prediction of biliary excretion in rats and humans using molecular weight and quantitative structure-pharmacokinetic relationships. AAPS J 11:511-525.

Zwolska Z, Niemirowska-Mikulska H, Augustynowicz-Kopec E, Walkiewicz R, Stambrowska H, Safianowska A, and Grubek-Jaworska H (1998) Bioavailability of rifampicin, isoniazid and pyrazinamide from fixed-dose combination capsules. Int J Tuberc Lung Dis 2:824-830.

Address correspondence to: Evita van de Steeg; or Lianne Stevens. E-mail: Lianne.stevens@tno.nl 